\title{
On the Empirical (Ir)Relevance of the Zero Lower Bound Constraint
}

Davide Debortoli, Universitat Pompeu Fabra, CREI, and Barcelona Graduate School of Economics

Jordi Galí, CREI, Universitat Pompeu Fabra, Barcelona Graduate School of Econom$i c s$, and NBER

Luca Gambetti, Collegio Carlo Alberto, Università di Torino, Universitat Autònoma de Barcelona, and Barcelona Graduate School of Economics

\section{Introduction}

The magnitude of the global financial crisis of $2007-8$ and the recession that it triggered led many central banks to lower their policy rates down to values near zero, their theoretical lower bound. ${ }^{1}$ In the United States, the target for the federal funds rate remained at zero for 7 years, from January 2009 through December 2015. During that period, the shortterm interest rate stopped playing its role as an instrument of macroeconomic stabilization. Was the performance of the US economy affected by the binding zero lower bound (ZLB)? The present paper seeks to provide an answer to that question. More specifically, our goal is to evaluate the merits of what we refer to as the "ZLB empirical irrelevance hypothesis" (or the "irrelevance hypothesis," for short), that is, the hypothesis that the economy's performance was not affected by the binding ZLB constraint, in practice, during the recent US episode. In particular, we focus on two dimensions of that performance that were ex ante likely to have experienced the impact of a binding ZLB: (i) the volatility of macro variables and (ii) the economy's response to shocks.

We start our empirical exploration with an assessment of the possible changes in the volatility of macro variables during the period in which the ZLB constraint was binding. A rise in volatility could have been expected as a result of the Fed's hands being tied because of the federal funds rate having hit the ZLB, since this prevented the "usual" stabilizing policy response to aggregate shocks. Yet we find little evidence of such an increase in volatility of either real or nominal US macro variables over the period during which the federal funds rate attained its ZLB. The previous finding is at odds with the predictions of a baseline New Keynesian (NK) model, as we show by means of a number of simulations, under 
the assumption that the central bank follows a simple interest rate rule that embeds the ZLB assumption.

In the second part of the paper, we ask ourselves whether the response of a variety of US macro variables (other than the policy rate itself) to different aggregate shocks changed during the binding ZLB episode. Our empirical approach involves the estimation of a structural vector autoregressive model with time-varying coefficients (TVC-SVAR), driven by four shocks that are identified by means of a combination of long-run and sign restrictions. Under the irrelevance hypothesis, there should not be any significant change in the estimated responses over the binding ZLB period relative to period before the ZLB was binding. This is indeed what we find. In particular, we show that the estimated response of the long-term interest rate during the ZLB period is very similar to its counterpart for the pre-ZLB period. Furthermore, when we estimate a "rule" for the long-term rate, we find little evidence of a break during the ZLB period.

The previous findings are consistent with (but not a proof of) the notion that the adoption and fine-tuning of unconventional monetary policies (UMPs) may have been highly effective during the ZLB period in steering the long rate as desired, despite an unchanged policy rate. To illustrate that interpretation, we show how the previous findings can be reconciled with the predictions of a baseline NK model when we assume an interest rate rule based on a shadow interest rate. That rule can be interpreted as capturing the role of forward guidance (i.e., the management of expectations on the future path of the policy rate) in getting around the constraints imposed by the ZLB.

We want to warn the reader at the outset against two possible misinterpretations of our findings. First, one may be tempted to view those findings as suggesting that, contrary to what mainstream economic theory implies in the presence of nominal rigidities, the ZLB is irrelevant "always and everywhere." Instead, our evidence focuses on a specific economy (the United States) and episode (the 2009Q1-2015Q4 period). Several unconventional programs were adopted by the Federal Reserve during that period, which may account for our evidence. A binding ZLB could very well have a different impact in a different context if unaccompanied by such unconventional policies.

Second, our "irrelevance" findings should not be interpreted as downplaying the significance of the Great Recession and the slowness of the subsequent recovery. Together with the associated deflationary pressures, they were undoubtedly the main factors behind the sharp reduction in the 
federal funds rate down to its ZLB. Our findings suggest, however, that no special role should be attributed to the ZLB constraint as explanation for the depth and persistence of the recession. Instead, the size, persistence, and financial nature of the shocks experienced by the US economy (before the start of the ZLB episode) are more likely explanations of the severity of the downturn, as had been the case for many other financial crises experienced by different countries in the past, and which did not generally involve a binding ZLB constraint. ${ }^{2}$

The remainder of the paper is organized as follows. Section II discusses the related literature. Section III provides evidence on the impact of the binding ZLB on macroeconomic volatility. Section IV contrasts that evidence with the predictions of a baseline NK model. Section V studies how the binding ZLB constraint may have affected the economy's response to a variety of shocks. Section VI analyzes the ability of a modified interest rate rule to account for the empirical evidence. Section VII summarizes and concludes.

\section{Related Literature}

Our work is close in spirit to papers that seek to evaluate, using different approaches, some form of ZLB irrelevance hypothesis. Thus, Swanson and Williams (2014) estimate the time-varying sensitivity of yields to macroeconomic announcements using high-frequency data and conclude that long-term yields were essentially unconstrained throughout 2008-12 and short-term yields seemed to be constrained only by late 2011 . Similarly, Campbell et al. (2012) provide evidence suggesting that forward guidance announcements by the Federal Open Market Committee have been successful in moving interest rates that are relevant for households' and firms' decisions, despite the binding ZLB constraint.

The recent works of $\mathrm{Wu}$ and $\mathrm{Xia}$ (2016) and $\mathrm{Wu}$ and Zhang (2017) are also closely related to our paper. Thus, Wu and Xia (2016) propose a shadow rate indicator as a measure of the monetary policy stance that also applies to binding ZLB periods. They embed their shadow rate in an identified factor-augmented vector autoregressive model similar to that in Bernanke, Boivin, and Eliasz (2005) and find that (exogenous) changes in the shadow rate have an effect on the economy during the ZLB period similar to the federal funds rate in the pre-ZLB period. A counterfactual simulation, in which the shadow rate is prevented from becoming negative, points to large real effects of having a persistently negative shadow rate during the ZLB period, which they attribute to the 
adoption of UMPs. Wu and Zhang (2017) study a NK model where aggregate demand is a function of a shadow rate that is not subject to a ZLB constraint and that is determined according to a conventional Taylor-type rule. The equilibrium dynamics are thus equivalent to those of the standard NK model without a ZLB constraint. Wu and Zhang discuss alternative channels through which the central bank can lower the shadow rate below zero, including purchases of assets by the central bank (combined with a preferred habitat-like assumption), direct lending to firms, and/or changes in tax rates on interest income. They conclude that a binding ZLB constraint on the policy rate does not have to alter the responses of aggregate variables to supply and demand shocks relative to periods with a nonbinding ZLB, as long as the central bank manages to adjust the shadow rate suitably.

Christiano, Eichenbaum, and Trabandt (2015) estimate and analyze a dynamic stochastic general equilibrium (DSGE) model that incorporates a truncated shadow rule similar to the one considered later. They use the estimated model to interpret the Great Recession. They attribute the bulk of the fall in output to a drop in total factor productivity and a rise in the cost of working capital, with counterfactual simulations without a ZLB constraint suggesting that the latter played a small role in accounting for the drop in output. That finding contrasts with Gust et al. (2017), who carry out a similar counterfactual experiment and find that $30 \%$ of the output contraction observed during the Great Recession can be attributed to the constraint imposed by the ZLB on the ability of monetary policy to stabilize the economy, with that constraint playing an even larger role in accounting for the slow recovery. Those estimates are, however, subject to large uncertainty. ${ }^{3} \mathrm{~A}$ similar finding was obtained in Del Negro et al. (2017), whose counterfactual simulations of a DSGE model with financial frictions suggest that the ZLB constraint can explain about onehalf of the $6 \%$ decline in output that would have been observed in the absence of unconventional interventions.

Our findings point to the benefits of adopting a shadow rule with sufficient inertia, which we interpret as a shortcut for UMPs. A number of papers have also uncovered a similar result using alternative models and assumptions, including Reifschneider and Roberts (2006), Kiley and Roberts (2017), and Bernanke, Kiley, and Roberts (2019).

Cochrane (2018) notes the absence of a break in the dynamics of US inflation and, in particular, the absence of a rise in inflation volatility during the binding ZLB episode. He argues that such an observation is 
inconsistent with the NK model, unless the fiscal theory of the price level is invoked. Our analysis in Section VI provides an alternative explanation for that observation, based on the use of forward guidance as a stabilizing tool.

Other authors have uncovered a change in asset price dynamics associated with the binding ZLB episode. Thus, Gourio and Ngo (2018) document a switch in the sign of the correlation between inflation and stock returns after 2008, which they attribute to the binding ZLB. Using a standard NK model, they show how the binding ZLB amplifies (dampens) the impact of demand (supply) shocks, lowering both inflation and term premia in long-term interest rates, which may partly account for the latter's unusually low levels since 2008. Similarly, Datta et al. (2019) document a substantial rise in the correlation between oil and equity returns, as well as a large responsiveness of those variables to news announcements, during the binding ZLB episode and show that finding can be reconciled with a NK model embedding the ZLB constraint.

Our paper, and the literature described earlier, can be seen as complementing the extensive work aimed at assessing the effects of UMPs and, in particular, the effects of UMP announcements or their implementation on financial variables. Examples of that work include Krishnamurthy and Vissing-Jorgensen (2011), Hamilton and Wu (2012), D'Amico and King $(2013,2017)$, and Swanson (2018), among many others.

Throughout the paper, we maintain the assumption of an unchanged inflation target, which we take as exogenously given. A branch of the literature has instead focused on the determination of the optimal inflation rate in the presence of the ZLB constraint, given the trade-off between the distortions associated with a higher average inflation and the benefits from it in the form of a smaller incidence of a binding ZLB. Contributions to that branch of the literature include Coibion, Gorodnichenko, and Wieland (2012), Dordal-i-Carreras et al. (2016), Blanco (2019), Kiley and Roberts (2017), and Andrade et al. (2018).

\section{Macroeconomic Volatility and the ZLB: Some Evidence}

We start with an empirical assessment of the impact of the binding ZLB constraint on US macroeconomic volatility. We report statistics for gross domestic product (GDP) and total hours in the nonfarm business sector (both in log first differences), as well as three measures of quarterly inflation based, respectively, on the GDP deflator, the core consumer 
price index (CPI), and the core personal consumption expenditure (PCE) deflator. All data are quarterly. The first column of table 1 reports the standard deviation of several macro variables over the ZLB episode (2009Q1-2015Q4) relative to the corresponding standard deviation during the period 1984Q1-2018Q2 but excluding the binding ZLB episode (henceforth, the no-ZLB period). Note that 1984 is often viewed as the date marking the beginning of the Great Moderation. The second column reports an analogous statistic, but excluding from both the no-ZLB and ZLB periods the observations corresponding to the Great Recession (2008Q1-2009Q2, according to the NBER chronology).

The previous statistics show little evidence of an increase in macro volatility during the ZLB period. Many of the ratios of standard deviations are below 1 , suggesting if anything a decline in volatility during the ZLB period. The previous statistics contrast starkly with the volatility in the pre-1984 period relative to the same benchmark, shown in the last column. In the latter case, the ratio of standard deviations is well above 1 for all the variables considered. ${ }^{4}$

Table 2 provides additional evidence pertaining to potential changes in volatility during the ZLB episode. It reports the estimates from an ordinary least squares (OLS) regression of the absolute value of the deviation of each variable (i.e., GDP growth, hours growth, and each of the three inflation measures) from a (period-specific) mean, on a constant and a dummy variable for the ZLB episode. ${ }^{5}$ Together with each point estimate, we report the corresponding standard errors, computed using the Newey-West estimator with a four-lag window. As a robustness check, we also report estimates from regressions that include a dummy for the

Table 1

Ratio of Standard Deviations

\begin{tabular}{lccc}
\hline & ZLB (1) & ZLB (2) & Pre-84 \\
\hline GDP & .92 & .89 & 2.19 \\
Hours & 1.32 & .74 & 1.60 \\
GDP deflator & 1.02 & .88 & 3.11 \\
Core CPI & .52 & .54 & 3.03 \\
Core PCE & .52 & .50 & 2.52 \\
\cline { 2 - 4 } Great Recession? & Yes & No & No \\
\hline
\end{tabular}

Note: Standard deviations are computed relative to the no-ZLB period given by 1984Q1-2008Q4 and 2016Q1-2018Q2. The ZLB period is 2009Q1-2015Q4. When the Great Recession is excluded, the pre-ZLB sample period ends in 2007Q4 and the ZLB period starts in 2009Q3. The Pre-84 period starts in 1960Q1 and ends in 1983Q4. ZLB = zero lower bound; GDP = gross domestic product; $C P I=$ consumer price index; $\mathrm{PCE}=$ personal consumption expenditure. 
Table 2

Volatility Regressions

\begin{tabular}{lccc}
\hline & CONST & ZLB & GR \\
\hline GDP & $.41^{*}$ & .01 & \\
& $(.04)$ & $.05)$ & \\
& $.37^{*}$ & -.01 & $.94^{*}$ \\
Hours & $(.03)$ & $(.05)$ & $(.19)$ \\
& $.47^{*}$ & .05 & \\
& $(.05)$ & $(.16)$ & \\
GDP deflator & $.42^{*}$ & -.00 & $1.39^{*}$ \\
& $(.04)$ & $. .09)$ & $(.42)$ \\
& $.70^{*}$ & $(.12)$ & \\
Core CPI & $(.07)$ & .03 & \\
& $.69^{*}$ & .02 & .37 \\
& $(.07)$ & $(.11)$ & $(.26)$ \\
Core PCE & $.91^{*}$ & $-.47^{*}$ & \\
& $(.10)$ & $(.13)$ & \\
& $.91^{*}$ & $-.47^{*}$ & -.05 \\
& $(.10)$ & $(.13)$ & $(.13)$ \\
& $.83^{*}$ & $-.41^{*}$ & \\
& $(.08)$ & $(.10)$ & $(.23)$ \\
& $.83^{*}$ & $-.42^{*}$ & .13 \\
\hline
\end{tabular}

Note: The table reports the estimated coefficients from an ordinary least squares regression of the absolute value of the deviation of each variable's growth rate from its mean, on a constant (CONST) and a dummy for the zero lower bound (ZLB) period (2009Q1-2015Q4), with and without a control dummy for the Great Recession (GR) period (2008Q1-2009Q2). The sample period is 1984Q1-2018Q2. Standard errors obtained using a Newey-West estimator (4 lags). GDP $=$ gross domestic product; $\mathrm{CPI}=$ consumer price index; $\mathrm{PCE}=$ personal consumption expenditure.

*denotes statistical significance at the $5 \%$ level.

Great Recession in addition to the ZLB period. The eventual impact of the binding ZLB on the volatility of each variable should be captured by the estimated coefficient of the ZLB dummy in the corresponding regression. As the estimates reported in table 2 indicate, there is no evidence of a significant volatility increase during the ZLB period in any of the variables considered, for any specification. By contrast, we find two instances of a significant reduction in volatility during that episode: this is the case for core CPI and core PCE inflation.

The evidence reported in tables 1 and 2 is reflected graphically in figure 1, which shows the evolution of GDP growth and inflation (based on the GDP deflator) over the period 1984Q1-2018Q2, with the binding ZLB episode marked with a shaded area. It is not obvious at all to the naked 

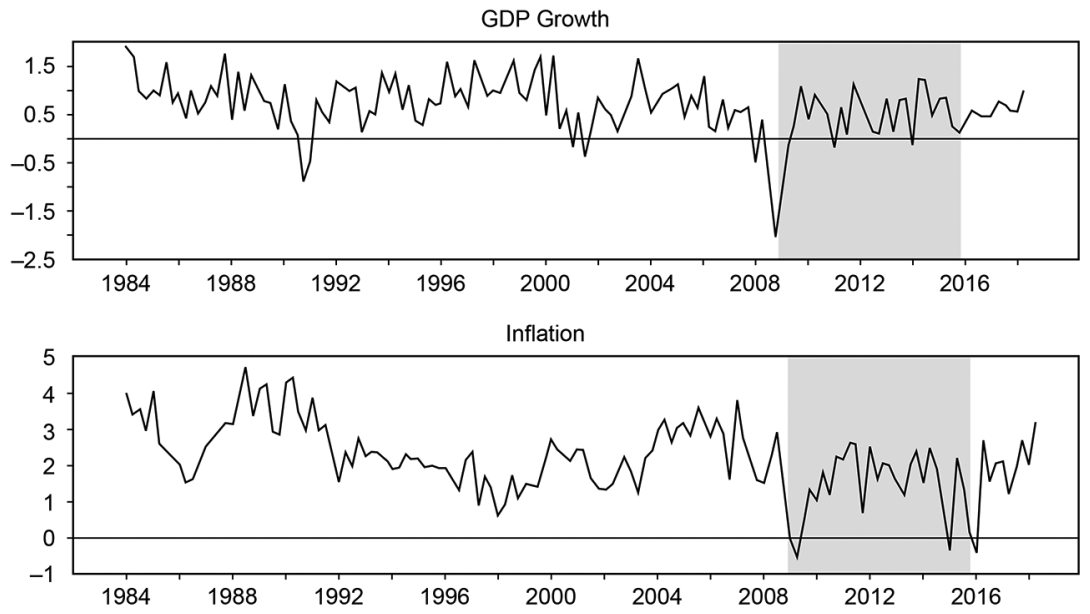

Fig. 1. Macroeconomic volatility and the zero lower bound. GDP = gross domestic product.

eye that the volatility of either variable was affected one way or another during the ZLB episode.

The evidence provided earlier contrasts with much of the literature on the effects of a binding ZLB constraint. The next section illustrates that contrast.

\section{Macroeconomic Volatility and the ZLB: Predictions of a Benchmark Model}

Next, we analyze the predictions of a baseline NK model regarding the implications of a binding ZLB constraint for the equilibrium behavior of different macroeconomic variables. Needless to say, we are not the first to carry out an analysis of this kind. Examples of related earlier work include Christiano, Eichenbaum, and Rebelo (2011), Eggertsson (2011), and Wieland (2019), among many others. In contrast with those papers, our focus here is on the implications of the binding ZLB constraint for macro volatility relative to "normal" times.

Our model is fully standard, so we restrict ourselves to describing its main elements. We assume an infinitely lived representative household with expected utility given by

$$
\mathbb{E}_{0}\left\{\sum_{t=0}^{\infty} \beta_{0, t}\left(\log C_{t}-\frac{N_{t}^{1+\varphi}}{1+\varphi}\right)\right\},
$$


where $C_{t}$ is a constant elasticity of substitution function (with elasticity of substitution $\epsilon>1$ ) of the quantities consumed of a continuum of differentiated goods and $N_{t}$ denotes hours worked. The discount factor $\beta_{0, t}$ is defined recursively by $\beta_{0, t}=\beta_{0, t-1} \exp \left\{-z_{t}\right\}$, for $t=1,2,3, \ldots$ with $\beta_{0,0} \equiv$ 1. Variable $z_{t}$ is the implied discount rate, which is assumed to follow a stochastic process with two components:

$$
z_{t}=\rho_{t}+\eta_{t}
$$

The first component, $\rho_{t}$, is a two-state Markov process, switching between a normal value $\rho>0$ and a low value $\rho_{L}<0$. The realization of the latter, which we interpret as a large adverse demand shock, pulls the short-term interest rate against the ZLB constraint, given the assumed policy rule. The second component, $\eta_{t}$, is meant to capture "regular" or "recurrent" demand shocks and is assumed to follow an AR(1) process:

$$
\eta_{t}=\rho_{\eta} \eta_{t-1}+\varepsilon_{t}^{\eta}
$$

where $\rho_{\eta} \in[0,1)$, and $\varepsilon_{t}^{\eta}$ is a white noise process with variance $\sigma_{\eta}^{2}$. For concreteness, in the simulations that follow, we restrict ourselves to shifts in the discount rate $z_{t}$ as a source of aggregate fluctuations.

The supply side is fully standard. We assume a continuum of identical monopolistically competitive firms, each facing a constant Calvo probability $\theta$ of not being able to reoptimize its price in any given period. Technology is given by $Y_{t}=N_{t}^{1-\alpha}$. All output is consumed. The labor market is perfectly competitive.

The log-linearized equilibrium conditions describing the private sector of this economy are given by the familiar NK Phillips curve and dynamic investment/saving equations:

$$
\begin{aligned}
& \hat{\pi}_{t}=\beta \mathbb{E}_{t}\left\{\hat{\pi}_{t+1}\right\}+\kappa \hat{y}_{t} \\
& \hat{y}_{t}=\mathbb{E}_{t}\left\{\hat{y}_{t+1}\right\}-\left(i_{t}-\mathbb{E}_{t}\left\{\pi_{t+1}\right\}-z_{t}\right)
\end{aligned}
$$

where $\hat{\pi}_{t} \equiv \pi_{t}-\pi$ and $\hat{y}_{t} \equiv y_{t}-y$ respectively denote the deviation of inflation and (log) output from their steady-state values, $i_{t}$ is the short-term (one-period) nominal interest rate, $\beta \equiv \exp \{-\rho\}$ and $\kappa \equiv(1-\theta)(1-\beta \theta)$ $(1+\varphi) / \theta(1-\alpha+\alpha \epsilon){ }^{6}$ It can be easily checked that under our assumptions the natural (flexible price) level of output is constant (and corresponds to the steady state), and $z_{t}$ has the interpretation of the natural (flexible price) rate of interest.

The model is closed by assuming a monetary policy rule. As an empirically plausible baseline, we consider the following "truncated" version of a Taylor-type rule with inertia: 


$$
i_{t}=\max \left[0, \phi_{i} i_{t-1}+\left(1-\phi_{i}\right)\left(\rho+\pi+\phi_{\pi} \hat{\pi}_{t}+\phi_{y} \Delta \hat{y}_{t}\right)\right],
$$

Next, we analyze the equilibrium behavior of a long-term interest rate, which we define as the yield on a pure discount bond with stochastic maturity. More precisely, the long-term bond is assumed to mature each period with probability $1-\gamma$, in which case it pays one unit of the numéraire (and yielding no payoff otherwise). The (normalized) yield of that bond, denoted by $i_{t}^{L}$, can be shown to satisfy the following difference equation in equilibrium (and up to a first-order approximation):

$$
i_{t}^{L}=(1-\beta \gamma) i_{t}+\beta \gamma E_{t}\left\{i_{t+1}^{L}\right\} .
$$

We adopt a quarterly calibration of the model. We assume $\theta=0.75$, which implies an average price duration of four quarters. The coefficients of the policy rule are set to $\phi_{\pi}=1.5, \phi_{y}=0.5$, and $\phi_{i}=0.7$, in line with the empirical evidence. Steady-state inflation $\pi$ is set to 0.005 , consistent with an (annual) inflation target of $2 \%$. We assume $\alpha=0.25$ and $\varphi=1$, both conventional values. We set $\epsilon=6$, implying a flexible price markup of $20 \%$. We assume $\rho_{\eta}=0.8$ and $\sigma_{\eta}=0.001$. Under the previous settings, the standard deviation of quarterly output growth when the ZLB is not binding is about $0.7 \%$, consistent with that of US GDP growth over the 1984Q1-2008Q4 period. We set $\rho=0.005$, implying an average real rate of $2 \%$ in normal times. We assume $\rho_{L}=-0.01$ so that a large adverse demand shock implies a natural rate of $-4 \%$ in annual terms (and in the absence of other recurrent shocks). The probability of remaining in the normal regime is 0.994 , whereas the probability of remaining in the low demand regime is 0.66 . These values imply that ZLB episodes occur on average once every 140 quarters, with each episode expected to last 3 quarters. Under the previous settings, the contemporaneous impact on output of a large adverse demand shock (i.e., a Markov transition to $\rho_{L}$ ) is about $-4 \%$, which roughly corresponds to the observed decline in US GDP over the Great Recession. Most importantly for our purposes, the realization of a large adverse demand shock generally brings the policy rate down to zero, where it remains until the normal Markov state is restored again. Finally, we set $\gamma=0.975$, consistent with an expected maturity for the long-term bond of 40 quarters (i.e., 10 years).

Similarly to Fernández-Villaverde et al. (2015), we solve the model using a global projection method to accurately account for the uncertainty and the nonlinearities associated with the presence of the occasionally binding ZLB constraint. In particular, we approximate the policy functions for inflation, output, and interest rates with Chebyshev polynomials (or splines) through a collocation method on a discrete grid for the 
four state variables (lagged output and interest rate, and the two components of the demand shocks).

Figure 2 shows the dynamic responses of several macro variables to a negative $\eta_{t}$ shock, under the two possible states of the economy, namely, normal times (i.e., when the ZLB is nonbinding, shown in lines with filled circles) and under a binding ZLB regime (shown in lines with open diamonds). The figure illustrates clearly the destabilizing role of a binding ZLB in the face of an adverse demand shock relative to normal times: the inability to bring down the policy rate leads to much larger declines of output and inflation. Note that the long-term rate responds in opposite directions to the negative demand shock under the two scenarios. It declines in normal times, reflecting the expectations of a persistently lower short-term rate. In contrast, when the negative demand shock hits the economy during a binding ZLB episode, the long-term rate increases, reflecting the expectations of a (transitorily) higher path of short-term rates in the future, when the ZLB stops being binding, because in that case the economy would experience higher output growth in its transition to the new steady state, having started from a lower output level due to the current adverse demand shock. Note also that the contractionary effect of
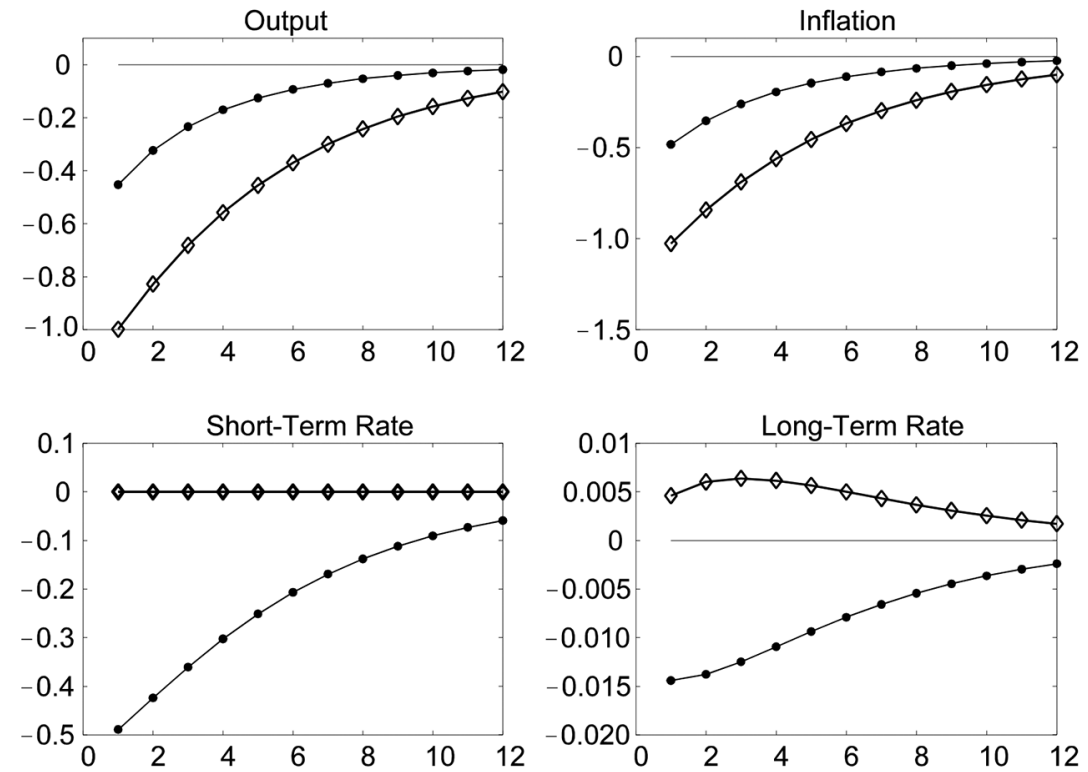

$\rightarrow$ Non-Binding ZLB $\multimap$ Binding ZLB

Fig. 2. The impact of a binding zero lower bound (ZLB) on the dynamic effects of a demand shock, baseline interest rate rule. 
higher expected nominal short-term rates (reflected in the higher longterm nominal rate) is further amplified by the deflationary expectations caused by the shock, leading to an even larger increase in the long-term real rate (not shown).

Figure 3 displays the time series for output growth and inflation around the time of a large adverse demand shock, based on a simulation of the calibrated model described earlier. The timing of the large adverse shock and its eventual undoing is indicated with two vertical dashed lines. The "tunnel" within which the time series evolves represents, for each period, a 95\% confidence interval for the realizations of the plotted variable across 1,000 simulations. The figure illustrates the increase in the volatility of output and inflation during the binding ZLB period relative to the earlier and later periods when the ZLB constraint is not binding. The model's predictions in that regard seem to conflict with the patterns of volatility observed in the US economy discussed in the previous section. Tables 3 and 4 formalize that visual intuition.

Table 3 reports the mean, across 1,000 model simulations, of the ratio of standard deviations of output growth and inflation over the binding ZLB episodes relative to normal times, together with a $95 \%$ confidence interval. In computing that ratio, we use simulations of the calibrated model for which the realized length of the binding ZLB period is equal to that observed in the recent US episode, namely, 28 quarters. As the
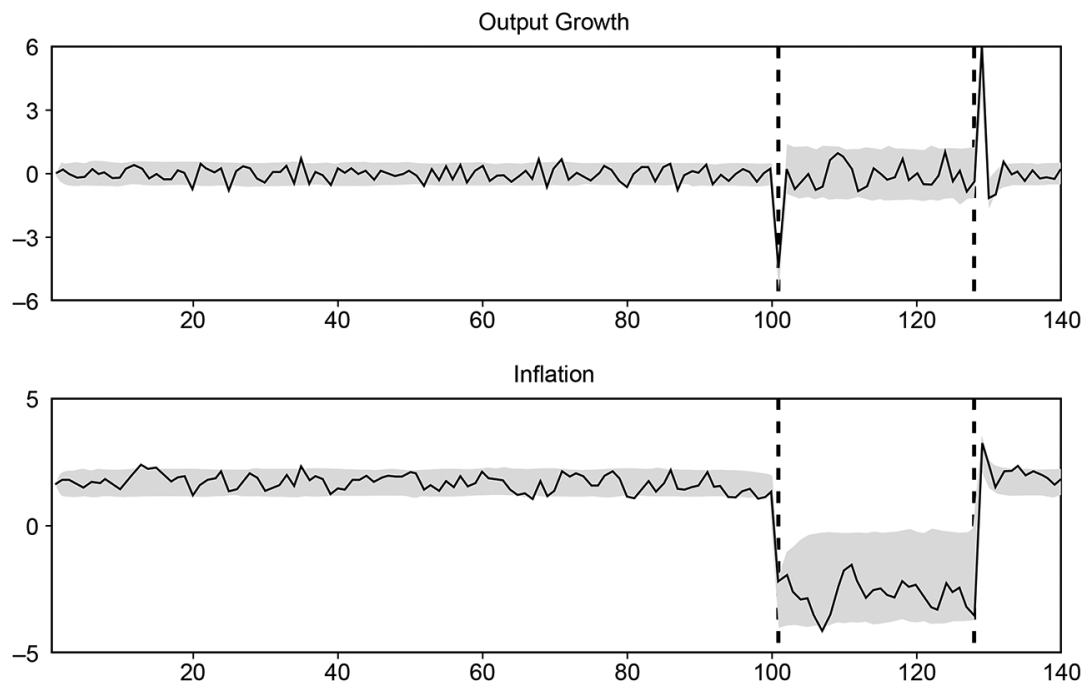

Fig. 3. Macroeconomic volatility and the zero lower bound: model simulations, baseline interest rate rule. 
Table 3

Relative Volatility: Simulations

\begin{tabular}{lcc}
\hline & \multicolumn{2}{c}{ Baseline Interest Rate Rule } \\
\cline { 2 - 3 } & \multicolumn{1}{c}{$(1)$} & $(2)$ \\
\hline Output & 1.49 & 2.29 \\
& {$[.86,2.37]$} & {$[1.69,2.95]$} \\
Inflation & 1.94 & 2.39 \\
& {$[.91,3.38]$} & {$[1.02,3.86]$} \\
\cline { 2 - 3 } Markov transitions? & \multicolumn{2}{c}{ Yes } \\
\hline
\end{tabular}

Note: For each variable, the table reports the mean of the standard deviation in the ZLB period relative to the no-ZLB period over 1,000 model simulations under the baseline interest rate rule. The no-ZLB period is given by the first 100 observations and the last 8 observations in the simulation. The ZLB period corresponds to the intermediate 28 observations. Statistics are calculated both including all the observations (column 1) and excluding the two Markov transition observations into and out of the ZLB period (column 2). Brackets indicate 95\% confidence intervals.

values reported in the table make clear, and in a way consistent with the impulse responses of figure 2 and the evidence in figure 3 , the binding ZLB episode is characterized by a much larger average volatility, especially when we exclude the Markov transition observations from the computation of the standard deviation (column 2).

Table 4

Volatility Regressions: Simulations

\begin{tabular}{lcccc}
\hline & \multicolumn{4}{c}{ Baseline Interest Rate Rule } \\
\cline { 2 - 5 } & CONST & ZLB & MT & \%REJ \\
\hline Output & $.32^{*}$ & $.35^{*}$ & & .86 \\
& {$[.27, .36]$} & {$[.16, .56]$} & & \\
& $.26^{*}$ & $.34^{*}$ & $4.15^{*}$ & .98 \\
\multirow{4}{*}{ Inflation } & {$[.23, .3]$} & {$[.19, .50]$} & {$[3.34,4.92]$} & \\
& $.27^{*}$ & $.47^{*}$ & & .98 \\
& {$[.23, .32]$} & {$[.21, .79]$} & & \\
& $.26^{*}$ & $.47^{*}$ & $.61^{*}$ & .98 \\
& {$[.22, .30]$} & {$[.22, .79]$} & {$[.02,1.31]$} & \\
\hline
\end{tabular}

Note: For each variable, the table reports the mean, over 1,000 model simulations under the baseline interest rate rule, of the estimated coefficients from an ordinary least squares regression of the absolute value of the demeaned growth rate of each variable on a constant (CONST), a dummy indicating the zero lower bound (ZLB) period, and, when it applies, a dummy for the two periods when a Markov transition (MT) occurs. Brackets indicate 95\% confidence bands. \%REJ is the fraction of simulations for which the estimated coefficient on the ZLB dummy is positive and statistically significant using the Newey-West estimate of the standard error (4 lags).

*denotes statistical significance at the 5\% level. 
Table 4 shows the estimated coefficients, using simulated data, from a regression of the absolute value of (demeaned) output growth and inflation on a ZLB dummy, with and without a control dummy for the two periods when a Markov transition occurs. ${ }^{7}$ The regression uses time series generated by 1,000 simulations of the calibrated model. Each time series has 138 observations, with a binding ZLB episode taking place between periods 101 and 128, that is, a pattern that corresponds to that observed in the empirical sample period used in the previous section. In addition to the mean estimated coefficients, we report the $95 \%$ confidence band across simulations (shown in brackets), as well as the fraction of simulations for which we reject the null of a zero coefficient on the ZLB dummy at the $5 \%$ significance level, using the Newey-West estimate of standard errors. Note that the means (as well as the $95 \%$ confidence band) of the estimated coefficients on the ZLB dummy are systematically positive, reflecting the increase in volatility associated with ZLB episodes. This is true for both output growth and inflation, and independently of whether we control for the periods with "large shocks," corresponding to the Markov transitions. The previous finding contrasts with the estimates of the corresponding regressions using US data and reported in table 2, and where most of the estimated coefficients on the ZLB dummy were insignificant, with the exception of a few instances in which they were significantly negative (thus pointing to a reduction in volatility). Finally, note that the large fraction of simulations (ranging between $86 \%$ and $98 \%$, depending on the variable and specification) for which the null of no change in volatility during the ZLB episode is rejected at the $5 \%$ significance level. The previous finding suggests that the relatively short ZLB period is not an obstacle for the changing volatility test to have a high power when the data are generated by our baseline calibrated model.

\section{Did the Binding ZLB Affect the Economy's Response to Shocks?}

In the present section, we use a TVC-SVAR to estimate the dynamic responses of a number of macro variables to several identified aggregate shocks. The main motivation for using a model with TVC lies in our interest in assessing the extent to which the binding ZLB episode implied a change in the way the economy responded to different shocks. In addition, the use of a TVC-SVAR provides a flexible specification that allows for other structural changes that the US economy may have experienced over the sample period used in the estimation. ${ }^{8}$ 


\section{A. Our Empirical Approach}

Let $\mathbf{x}_{t}=\left[\Delta\left(y_{t}-n_{t}\right), n_{t}, \pi_{t}, i_{t}^{L}\right]^{\prime}$, where $y_{t}$ is (log) output in the nonfarm business sector, $n_{t}$ denotes (log) hours of all persons in the nonfarm business sector, $\pi_{t}$ is GDP deflator inflation, and $i_{t}^{L}$ is the 10-year Treasury bond yield. Both output and hours are normalized by civilian population. All data are for the US economy, at a quarterly frequency, and cover the period 1953Q2 through 2015Q4. ${ }^{9}$ We assume that the evolution of $\mathbf{x}_{t}$ is described by the following TVC-VAR model:

$$
\mathbf{x}_{t}=\mathbf{A}_{0, t}+\mathbf{A}_{1, t} \mathbf{x}_{t-1}+\mathbf{A}_{2, t} \mathbf{x}_{t-2}+\ldots+\mathbf{A}_{p, t} \mathbf{x}_{t-p}+\mathbf{u}_{t}
$$

where $\mathbf{A}_{0, t}$ is a vector of time-varying intercepts, $\mathbf{A}_{i, t}$, for $i=1, \ldots, p$, are matrices of TVCs, and $\mathbf{u}_{t}$ is a Gaussian white noise vector process with covariance matrix $\boldsymbol{\Sigma}_{t}$. We assume the reduced-form innovations $\mathbf{u}_{t}$ are a linear transformation of the underlying structural shocks $\boldsymbol{\varepsilon}_{t}$ given by

$$
\mathbf{u}_{t} \equiv \mathbf{Q}_{t} \boldsymbol{\varepsilon}_{t}
$$

where $\mathbb{E}\left\{\boldsymbol{\varepsilon}_{t} \boldsymbol{\varepsilon}_{t}^{\prime}\right\}=I$ and $\mathbb{E}\left\{\boldsymbol{\varepsilon}_{t} \boldsymbol{\varepsilon}_{t-k}^{\prime}\right\}=0$ for all $t$ and $k=1,2,3, \ldots$ It follows that $\mathbf{Q}_{t} \mathbf{Q}_{t}^{\prime}=\boldsymbol{\Sigma}_{t}$.

Following Primiceri (2005), we assume that the coefficients of the autoregressive matrices $\left\{\mathbf{A}_{i, t}\right\}$ and the covariance matrix $\boldsymbol{\Sigma}_{t}$ follow random walks, as described in detail in the appendix. The resulting reducedform model is estimated as in Del Negro and Primiceri (2013). Given the estimated reduced-form VAR for any given period $t$, we recover the reduced-form moving average (MA) representation

$$
\mathbf{x}_{t}=\boldsymbol{\mu}_{t}+\mathbf{B}_{t}(L) \boldsymbol{u}_{t}
$$

where $\boldsymbol{\mu}_{t}$ is a vector of time-varying means and $\mathbf{B}_{t}(L)$ is a polynomial of (time-varying) matrices.

The identifying restrictions assumed in the following allow us to determine the linear mapping $\mathbf{Q}_{t}$. Given the latter, we can write the structural MA representation as

$$
\mathbf{x}_{t}=\boldsymbol{\mu}_{t}+\mathbf{C}_{t}(L) \boldsymbol{\varepsilon}_{t}
$$

where $\mathbf{C}_{t}(L) \equiv \mathbf{B}_{t}(L) \mathbf{Q}_{t}$ describes the dynamic responses of the economy in period $t$. The possible changes over time in those responses are the focus of our analysis. Next, we turn to the determination of $\mathbf{Q}_{t}$, that is, to the issue of identification. 


\section{B. Identification}

We assume fluctuations in $\mathbf{x}_{t}$ are driven by four structural shocks, represented by the elements of vector $\varepsilon_{t}$ : technology, demand, monetary policy, and temporary supply shocks. We use a mix of long-run and sign restrictions to identify those shocks as follows: (i) the technology shock is the only one with a permanent effect on labor productivity; (ii) a demand shock generates a positive comovement of prices, GDP, and the long-term interest rate; (iii) a monetary policy shock generates a positive comovement between prices and GDP, but a negative one between the previous variables and the long-term interest rate; (iv) a transitory supply shock (e.g., a markup shock) implies a negative comovement of inflation and GDP. All the restrictions on the sign of comovements refer to a 1-year horizon. The long-run restriction used to identify technology was first proposed in Gali (1999). The sign restrictions are consistent with the predictions of a standard NK model under a plausible policy rule and are generally satisfied by estimated DSGE models (e.g., Smets and Wouters 2007). In the appendix, we discuss how the previous identification strategy is implemented in practice.

\section{Evidence}

Figure $4 a$ displays the estimated impulse responses of output, inflation, and the long rate (in both nominal and real terms) to the four shocks considered. The responses plotted correspond to the averages of the estimated responses for the pre-ZLB period 2002Q1-2008Q4 (shown in lines with filled circles) and the ZLB period 2009Q1-2015Q4 (lines with open diamonds). Note that both subsamples contain 28 periods. We also display $68 \%$ and $95 \%$ confidence bands for the average impulse responses in the pre-ZLB period, based on 500 draws from the posterior distribution of the estimated model. ${ }^{10}$

The differences in the estimated responses between the two periods are very small for all variables and shocks considered. In particular, the estimated responses of output and inflation for the two periods lie almost on top of each other. Most importantly, note that the lack of a significant gap between the responses in the two periods carries over to both the nominal and real long-term yields, which are arguably more relevant in the determination of aggregate demand than the short-term nominal rate (which does not adjust during the binding ZLB period). Although the response of both the nominal and real long-term rates over the ZLB period 


\section{A}
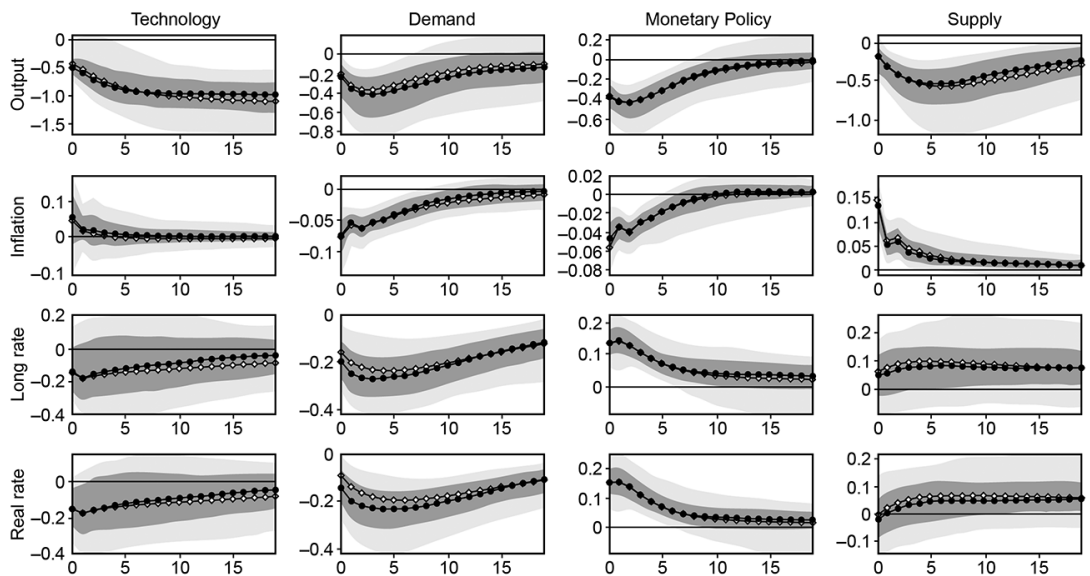

- 2002Q1-2008Q4

$\diamond 2009 Q 1-2015 Q 4$

\section{B}
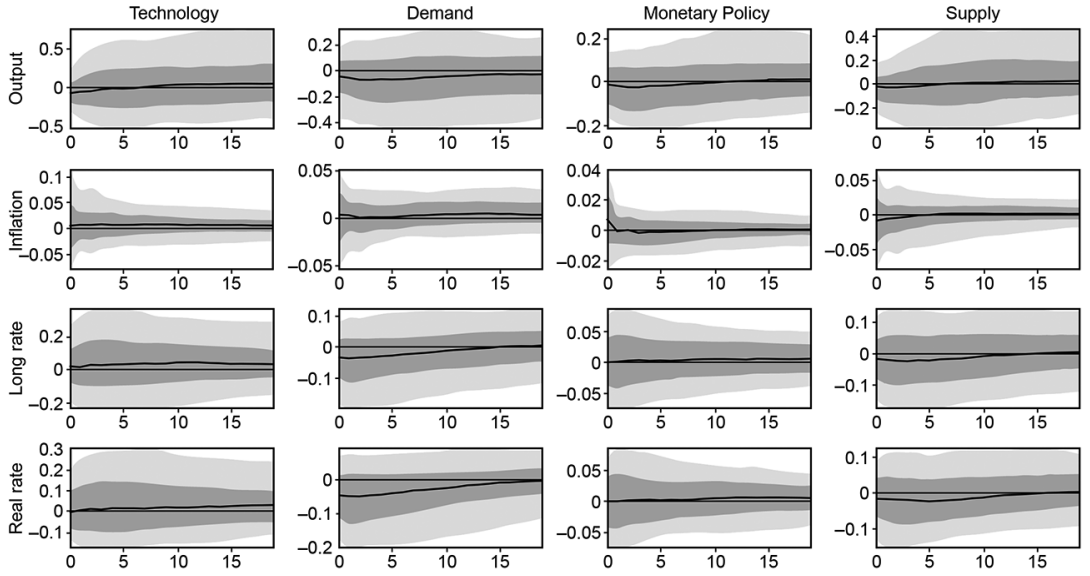

Fig. 4. (a) Dynamic responses: the impact of the binding zero lower bound (ZLB), short sample. (b) Dynamic response differentials: the effect of the binding ZLB, short sample. (c) Dynamic responses: the effect of the binding ZLB, short sample excluding the Great Recession. (d) Dynamic responses: the effect of the binding ZLB, extended pre-ZLB sample. 


\section{C}
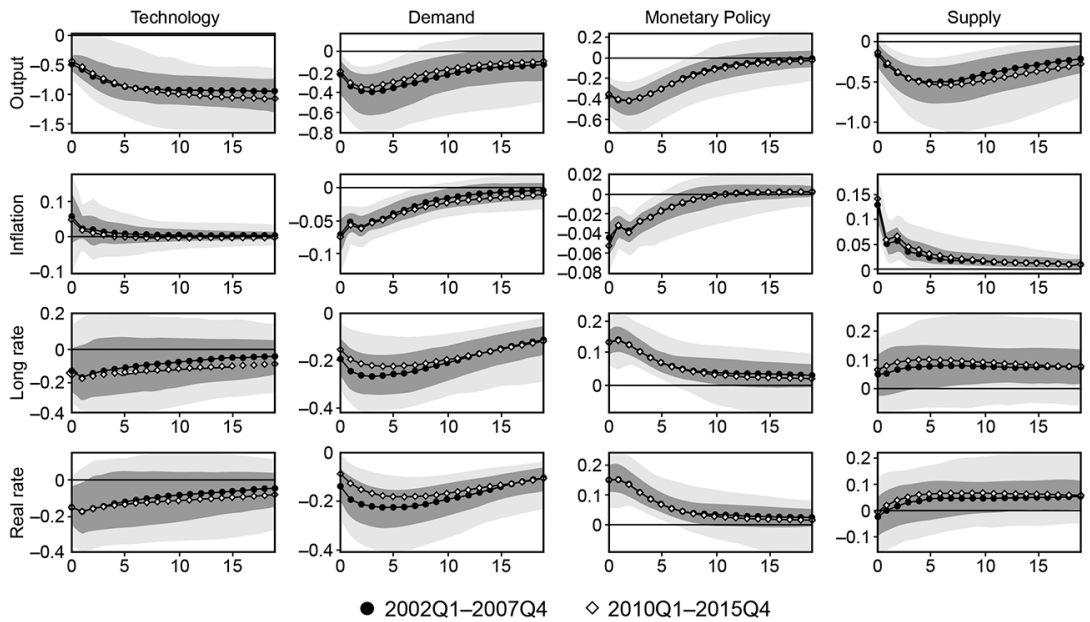

$\diamond 2010 Q 1-2015 Q 4$

\section{D}
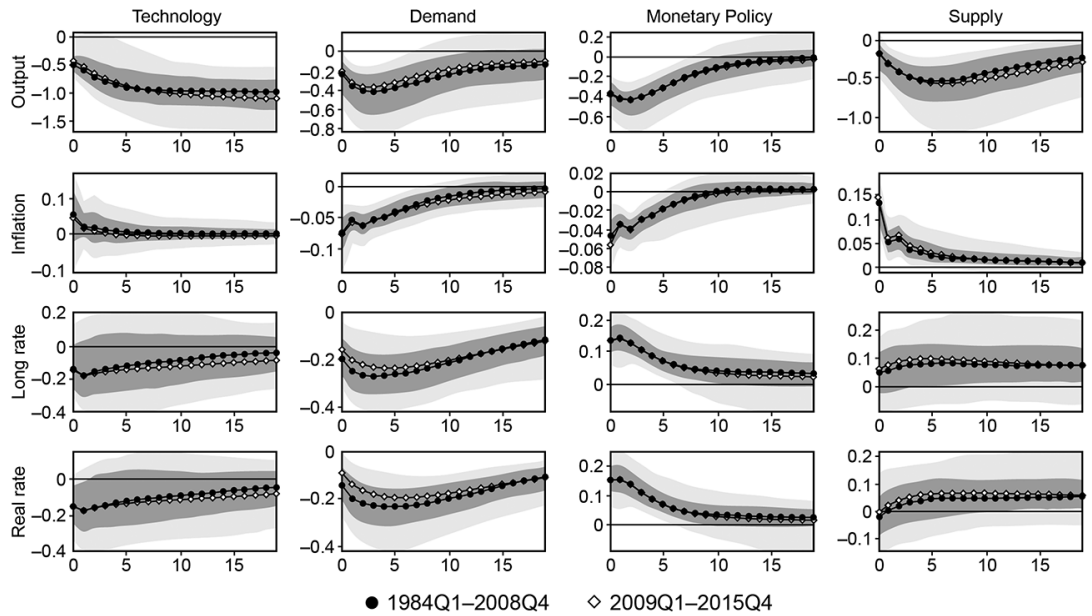

Fig. 4. Continued.

appears slightly muted relative to the pre-ZLB period, the difference is quantitatively very small and statistically insignificant. Figure $4 b$ displays the corresponding impulse response differentials with their associated confidence bands. One cannot reject the null of a zero differential response for any variable, even at a $32 \%$ significance level. 
The finding of similar responses of the long-term rate across the two subsample periods is consistent with our irrelevance hypothesis. Though we do not offer any direct evidence in that regard, that finding suggests that-possibly through the use of unconventional policies like forward guidance and quantitative easing - the Fed managed to steer long-term rates "as in normal times" in response to shocks hitting the economy during the ZLB period, thus leading to similar responses of output and inflation.

A caveat that might be raised regarding the evidence reported in figure $4 a$ and $4 b$ is that the estimated impulse responses may be somehow distorted by the Great Recession, which overlaps with both the pre-ZLB and ZLB periods. Figure $4 c$ reports estimates of average impulse responses for the pre-ZLB and ZLB periods but excluding from the respective averages the estimated responses for the Great Recession quarters (i.e., those between 2008Q1 and 2009Q2). None of the qualitative findings discussed earlier seem to be affected by the exclusion of that episode.

An additional potential caveat is that the methodology used may not be able to capture changes in dynamics that take place suddenly, as opposed to gradually over time. Figure $4 d$ seeks to dispel that concern by comparing the average impulse responses over the ZLB period with the median estimated average response across 500 draws, with each draw corresponding to a sample period of 28 consecutive observations, drawn randomly from the set $\{1984 Q 1: 1990 Q 4, \ldots, 2002 Q 1: 2008 Q 4\} .{ }^{11}$ The resulting estimates are once again very similar across the two periods, suggesting a relatively uniform response over the entire post-1984 period.

We conclude this section by providing an alternative perspective on the irrelevance hypothesis and the possible role played by the long-term interest rate in getting around the ZLB constraint. Consider the following (admittedly ad hoc) descriptive rule for the long-term interest rate

$$
i_{t}^{L}=\phi_{0}+\phi_{i} i_{t-1}^{L}+\left(1-\phi_{i}\right)\left[\phi_{\pi} \pi_{t}+\phi_{y} \Delta y_{t}\right]+\varepsilon_{t}^{m},
$$

where $\varepsilon_{t}^{m}$ is interpreted as an exogenous monetary policy shock. We estimate equation (4) and try to uncover changes in the coefficients on inflation and output growth by including as right-hand variables multiplicative dummies for the binding ZLB period and examining their significance. Furthermore, and to overcome the likely endogeneity of the regressors with respect to the policy shock $\left\{\varepsilon_{t}^{m}\right\}$, we estimate equation (4) using the time series for $\left\{i_{t}^{L}, \pi_{t}, \Delta y_{t}\right\}$, obtained after subtracting from each of them the corresponding component associated with the monetary policy shock in the estimated TVC-SVAR model described earlier. ${ }^{12}$ 
Table 5

Estimated Long-Term Interest Rate Rules

\begin{tabular}{lcccc}
\hline & $(1)$ & $(2)$ & $(3)$ & $(4)$ \\
\hline$\pi_{t}$ & $2.42^{*}$ & $2.82^{*}$ & $2.26^{*}$ & $2.61^{*}$ \\
& $(.61)$ & $(.82)$ & $(.23)$ & $(.32)$ \\
$\pi_{t} \times \mathrm{ZLB}_{t}$ & -.08 & -.01 & $-.17^{*}$ & -.45 \\
\multirow{2}{*}{$\Delta y_{t}$} & $(.08)$ & $(.06)$ & $(.06)$ & $(.50)$ \\
\multirow{2}{*}{$\Delta y_{t} \times \mathrm{ZLB}_{t}$} & & & $3.52^{*}$ & $4.43^{*}$ \\
& & & $(.42)$ & $(.58)$ \\
$\phi_{0}$ and $\phi_{i}$ dummies? & & & -.16 & -.60 \\
\cline { 2 - 5 } & & & $(.08)$ & $(.89)$ \\
\hline
\end{tabular}

Note: The table reports the ordinary least squares estimates of the longterm rate rule described in the text, both without output growth (first two columns) and with output growth (last two columns), with multiplicative dummies for the binding zero lower bound (ZLB) period. Column (2) and (4) also include ZLB dummies for the constant term $\left(\phi_{0}\right)$ and the coefficient on the lagged interest rate $\left(\phi_{i}\right)$. All the estimates are obtained using the nonmonetary component of the long-term interest rate, inflation, and output growth obtained from the estimated time-varying vector autoregressive model with time-varying coefficients.

*denotes statistical significance at the $5 \%$ level.

Under our assumptions, the resulting "cleansed" variables should be uncorrelated with the monetary policy shock, so that equation (4) can be estimated consistently using OLS. Table 5 reports the corresponding estimated coefficients, using two alternative specifications (with and without output growth in the rule). The reported estimates of the inflation and output growth coefficients point to a strong and highly significant response to both variables. In particular, the estimate of $\phi_{\pi}$ is well above 1, implying that the estimated rule satisfies the so-called Taylor principle. Most interesting, however, is the insignificance of the estimated coefficient on the multiplicative dummies associated with the binding ZLB period, suggesting the absence of a discernable change in the systematic response of the long-term interest rate to inflation and output growth as a consequence of the ZLB constraint becoming binding.

\section{Reconciling Theory and Evidence}

The earlier empirical findings lend support, overall, to the irrelevance hypothesis. One possible explanation for our findings is that the implementation of UMPs during the binding ZLB episode made it possible to 
steer the long-term interest rate as in normal times in response to developments in the economy. The absence of unconventional policies in the baseline NK model analyzed in Section IV may thus account for the discrepancy between our evidence and the model predictions.

In the present section, we study whether modifying the specification of monetary policy in our baseline model can help reconcile theory and evidence. In particular, and following Christiano et al. (2015), Gust et al. (2017), and Andrade et al. (2018), among others, we replace the baseline interest rate rule (eq. [1]) with the following "shadow rate rule":

$$
i_{t}=\max \left[0, i_{t}^{s}\right]
$$

where $i_{t}^{s}$ is a shadow interest rate that is not subject to any lower bound and that evolves according to

$$
i_{t}^{s}=\phi_{i} i_{t-1}^{s}+\left(1-\phi_{i}\right)\left(\rho+\pi+\phi_{\pi} \hat{\pi}_{t}+\phi_{y} \Delta \hat{y}_{t}\right) .
$$

Figure 5 displays the dynamic responses to an adverse demand shock (i.e., a negative $\eta_{t}$ realization) under the previous rule, with all the parameters of the model (including the coefficients in the rule) calibrated
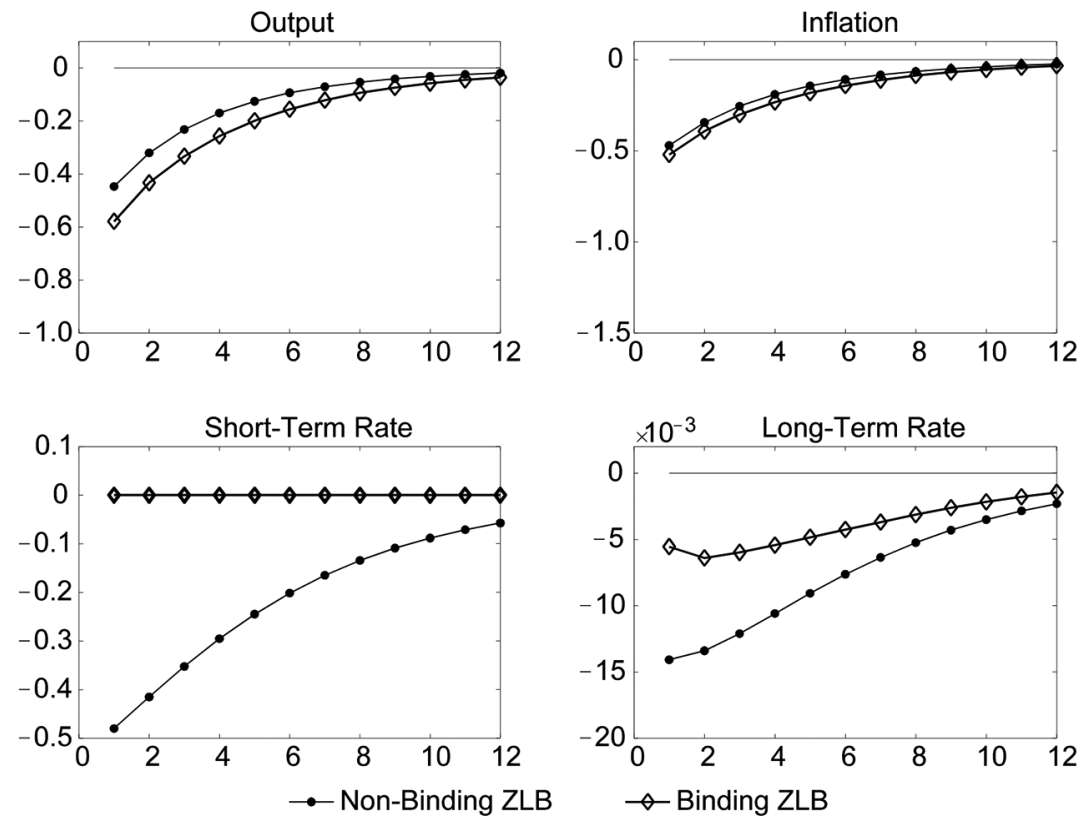

Fig. 5. The impact of a binding zero lower bound (ZLB) on the dynamic effects of a demand shock, shadow rate rule. 
as before. Impulse responses are displayed under the two regimes, characterized by a binding and a nonbinding ZLB. As the figure makes clear, the responses of output and inflation under the two regimes are now very similar, despite the large discrepancy in the responses of the shortterm rate (also displayed in the figure) due to the central bank's inability to lower that rate when the ZLB is binding. By contrast, the central bank manages to bring down the long-term nominal rate in response to the adverse demand shock, albeit not as much as under the nonbinding ZLB regime, and despite the lack of an adjustment in the short-term rule. The channel through which the shadow rate rule (eq. [6]) manages to stabilize the economy is one typically associated with forward guidance policies: the inertial term in equation (6), which is not bounded below, implies that the short-term rate will be kept "lower for longer" relative to the baseline rule (eq. [1]) in the aftermath of a binding ZLB episode, with the expected length of that additional stimulus being commensurate to the size of the decline in inflation and output, as well as the size of the inertial coefficient $\phi_{i}$.

Tables 6 and 7, based on simulations of the calibrated NK model with the shadow rate rule in place, report evidence on the implied changes in volatility during the binding ZLB period, in a way analogous to tables 3 and 4 for the baseline rule. Note that the estimates of the standard deviation of output growth and inflation in the binding ZLB period relative to the nonbinding ZLB period, shown in table 6, are noticeably lower than those in table 3, reflecting the gains in stability from the adoption

Table 6

Ratio of Standard Deviations: Simulations

\begin{tabular}{lcc}
\hline & \multicolumn{3}{c}{ Shadow Rate Rule } \\
\hline Output & 1.01 & $1.50^{*}$ \\
& {$[.65,1.9]$} & {$[1.03,1.94]$} \\
Inflation & .82 & 1.0 \\
& {$[.50,1.38]$} & {$[.59,1.41]$} \\
\cline { 2 - 3 } Markov transitions? & Yes & No
\end{tabular}

Note: For each variable, the table reports the mean of the standard deviation in the zero lower bound (ZLB) period relative to the pre-ZLB period over 1,000 model simulations under the baseline interest rate rule. The no-ZLB period is given by the first 100 observations and the last 8 observations in the simulation. The ZLB period corresponds to the intermediate $28 \mathrm{ob}-$ servations. Brackets indicate $95 \%$ confidence intervals. *denotes statistical significance at the $5 \%$ level. 
Table 7

Volatility Regressions: Simulations

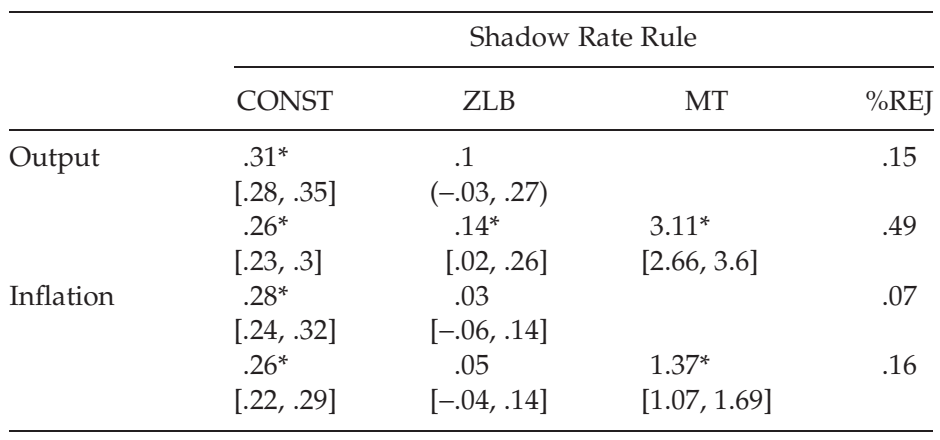

Note: For each variable, the table reports the mean over 1,000 simulations under the shadow rate rule of the estimated coefficients from an ordinary least squares regression of the absolute value of the demeaned growth rate of the variable on a constant (CONST), a dummy indicating the zero lower bound (ZLB) period, and, when it applies, a dummy for the period of a Markov transition (MT). Brackets indicate $95 \%$ confidence bands. \%REJ is the fraction of simulations for which the estimated coefficient on the ZLB dummy is positive and statistically significant using the Newey-West estimate of the standard error (4 lags).

*denotes statistical significance at the $5 \%$ level.

of the shadow rate rule. Furthermore, the reported relative standard deviations are comparable to some of the estimates in table 1 , obtained using actual US data. Similarly, the estimated volatility regressions reported in table 7 show very limited evidence of an increase in volatility during the binding ZLB episodes, with the implied fraction of simulations for which the null of no change in volatility is rejected at the $5 \%$ significance level being very small for most specifications (with a largest value of $49 \%$ ). The previous findings are visually captured by figure 6 , which displays the time series for output growth and inflation around the time of a large adverse demand shock, based on a simulation of our calibrated model under the shadow rate rule. In contrast to figure 3, which was based on simulations under the baseline rule, neither the volatility of the simulated series nor the width of the tunnel appear to change in a discernible way during the binding ZLB episode (the period between the two vertical dashed lines).

\section{Concluding Comments}

The ZLB empirical irrelevance hypothesis implies that an economy's performance is not affected, in practice, by a binding ZLB episode. The 

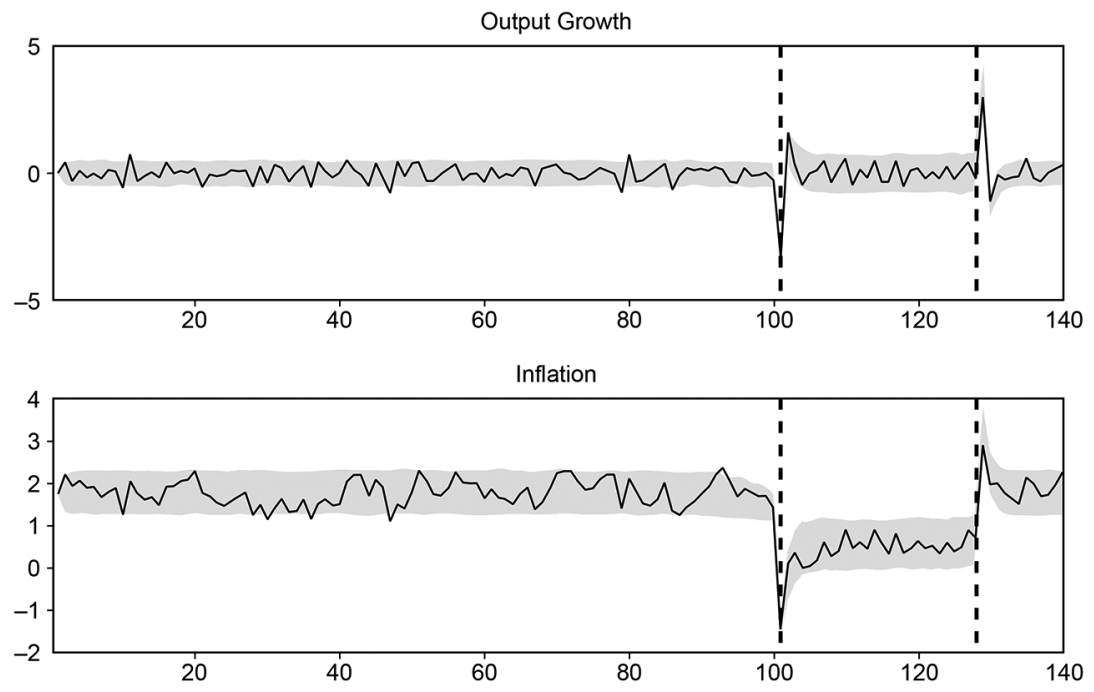

Fig. 6. Macroeconomic volatility and the zero lower bound: model simulations, shadow rate rule.

objective of the present paper was to evaluate that hypothesis for the recent ZLB episode experienced by the US economy (2009Q1-2015Q4). We have focused on two dimensions of performance that were ex ante likely to have experienced the impact of a binding ZLB: (i) the volatility of macro variables and (ii) the economy's response to a variety of macro shocks. Using several empirical approaches, we find little evidence against the irrelevance hypothesis, with our estimates suggesting that macro volatility did not increase significantly as a result of the binding ZLB constraint. Similarly, the responses of output, inflation, and the long-term interest rate to different shocks do not appear to have been much affected by that constraint. Our empirical findings can be reconciled with the predictions of a simple NK model under the assumption of a shadow interest rate rule, which can be viewed as capturing the effects of forward guidance policies that commit to lower for longer interest rates.

We interpret our findings as being consistent with (though not a proof of) the hypothesis that the UMPs implemented during the ZLB years may have succeeded, at least to some extent, at getting around the constraints imposed by the ZLB on conventional monetary policy.

Under that hypothesis, the unusual magnitude of the Great Recession and the slowness of the subsequent recovery in the US economy would 
be just the consequence of the large size, high persistence, and financial nature of the shock that triggered that recession, with no special amplifying role attributed to the binding ZLB constraint.

One should not interpret our evidence as suggesting that the ZLB constraint is irrelevant always and everywhere. A binding ZLB could very well have a much larger impact in a context different from the one that has been the object of analysis here.

\section{Appendix}

Let $\boldsymbol{\theta}_{t}=\operatorname{vec}\left(\mathbf{A}_{t}^{\prime}\right)$, where $\mathbf{A}_{t}=\left[\mathbf{A}_{0, t}, \mathbf{A}_{1, t} \ldots, \mathbf{A}_{p, t}\right]$ and $\operatorname{vec}(\cdot)$ is the column stacking operator. We assume $\boldsymbol{\theta}_{t}$ evolves over time according to the following equation:

$$
\boldsymbol{\theta}_{t}=\boldsymbol{\theta}_{t-1}+\omega_{t}
$$

where $\omega_{t}$ is a Gaussian white noise vector process with covariance matrix $\Omega$.

Time variation of $\boldsymbol{\Sigma}_{t}$ is modeled in the standard way. Let $\boldsymbol{\Sigma}_{t}=\mathbf{F}_{t} \mathbf{D}_{t} \mathbf{F}_{t}^{\prime}$, where $\mathbf{F}_{t}$ is lower triangular, with ones on the main diagonal, and $\mathbf{D}_{t}$ is a diagonal matrix. The vector containing the diagonal elements of $\mathbf{D}_{t}^{1 / 2}$, denoted by $\sigma_{t}$, is assumed to evolve according to the process

$$
\log \sigma_{t}=\log \sigma_{t-1}+\zeta_{t} .
$$

Moreover, let $\boldsymbol{\phi}_{i, t}$ denote the column vector with the nonzero elements of the $(i+1)$ th row of $\mathbf{F}_{t}^{-1}$. We assume

$$
\boldsymbol{\phi}_{i, t}=\boldsymbol{\phi}_{i, t-1}+\boldsymbol{v}_{i, t}
$$

where $\zeta_{t}$ and $\boldsymbol{\nu}_{i, t}$ are Gaussian white noise vector processes with zero mean and (constant) covariance matrices $\boldsymbol{\Xi}$ and $\boldsymbol{\Psi}_{i}$, respectively. We further assume that $\boldsymbol{\nu}_{i, t}$ is independent of $\boldsymbol{\nu}_{j, t}$, for all $j \neq i$, and that $\boldsymbol{\omega}_{t}, \boldsymbol{\varepsilon}_{t}, \boldsymbol{\zeta}_{t}$, and $\boldsymbol{\nu}_{i, t}$ (for all $i$ ) are mutually independent. Estimation is carried out as in Del Negro and Primiceri (2013). ${ }^{13}$

Reduced-form impulse response functions (IRFs) can be derived from the local moving average (MA) representation of the model. First, let us consider the companion form representation of equation (2):

$$
\tilde{\mathbf{x}}_{t}=\mathbf{a}_{t}+\tilde{\mathbf{A}}_{t} \tilde{\mathbf{x}}_{t-1}+\tilde{\mathbf{u}}_{t}
$$

where $\tilde{\mathbf{x}}_{t} \equiv\left[\mathbf{x}_{t}^{\prime}, \mathbf{x}_{t-1}^{\prime}, \ldots, \mathbf{x}_{t-p+1}^{\prime}\right]^{\prime}, \quad \tilde{\mathbf{u}}_{t} \equiv\left[\mathbf{u}_{t}^{\prime}, 0, \ldots, 0\right]^{\prime}, \quad \mathbf{a}_{t} \equiv\left[\mathbf{A}_{0, t}^{\prime}, 0, \ldots, 0\right]^{\prime}$, and $\tilde{\mathbf{A}}_{t}$ is the corresponding companion matrix. The (local) time-varying reduced-form MA representation of the model is given by 


$$
\mathbf{x}_{t}=\boldsymbol{\mu}_{t}+\sum_{j=0}^{\infty} \mathbf{B}_{t, j} \mathbf{u}_{t-j},
$$

where $\mathbf{B}_{t, j}=\left[\tilde{\mathbf{A}}_{t}^{j}\right]_{n, n}$, for $j=1,2, \ldots$, where $[\boldsymbol{M}]_{n, n}$ represents the first $n$ rows and $n$ columns of any matrix $\boldsymbol{M}$, and where $\mathbf{B}_{t, 0}=\mathbf{I}$.

The identification is implemented as follows. Let

$$
\mathbf{H}_{t}^{n}=\left(\begin{array}{ll}
1 & \mathbf{0}^{\prime} \\
\mathbf{0} & \mathbf{H}_{t}^{n-1}
\end{array}\right),
$$

where $\mathbf{0}$ is an $n$-dimensional column vector of zeros and $\mathbf{H}_{t}^{n}$ and $\mathbf{H}_{t}^{n-1}$ are orthogonal matrices of dimension $n \times n$ and $n-1 \times n-1$, The identification is implementedespectively. To impose the restrictions, we use the standard algorithm; see Uhlig (2005) and Rubio-Ramirez, Waggoner, and Zha (2010). We draw $\mathbf{H}_{t}^{n-1}$ using the QR decomposition and compute the implied structural IRFs as in equation (3) with $\mathbf{Q}_{t}=\mathbf{B}_{t}(1)^{-1} \mathbf{S}_{t} \mathbf{H}_{t}^{n}$, where $\mathbf{S}_{t}$ is the Cholesky factor of $\mathbf{B}_{t}(1) \Sigma_{t} \mathbf{B}_{t}^{\prime}(1)$. We retain the draw if the sign restrictions are satisfied. We collect a total of 500 draws at each point in time. With no loss of generality, we order the shocks as follows: technology, demand, monetary policy, and supply.

Sign restrictions for set identification require only qualitative implications from the theory. This can be seen as an advantage with respect to standard methods because contemporaneous exclusion restrictions are often arbitrary or hard to justify. The sign restriction approach, however, also presents a few drawbacks. As Baumeister and Hamilton (2015) show, the previous approach implies informative priors for the structural parameters and this might have implications for the analysis and the interpretation of the results. See also Watson's discussion of our paper in the present volume.

The average IRFs over the full pre-ZLB period are computed as follows:

1. Draw an integer between 1 and 78 with equal probabilities over the set of possible starting periods. Call it $t_{0}(j)$.

2. Take a draw from the distribution of IRFs (at all the horizons) from $t_{0}(j)$ up to $t_{0}(j)+27$, call it $x(t, j)$ with $t=t_{0}(j), \ldots, t_{0}(j)+27$ and $j=1$, $2, \ldots, 500$ (number of draws).

3. Compute the average IRF over the sample period drawn, $\bar{x}(t)=$ $(1 / 28) \sum_{t=t_{0}(j)}^{t_{0}(j)+27} x(t, j)$.

4. Repeat $1-3,500$ times. Compute the median and the percentiles of the corresponding $\bar{x}(t)$. 


\section{Endnotes}

Author email addresses: Debortoli (davide.debortoli@upf.edu), Galí (jgali@crei.cat), Gambetti (luca.gambetti@uab.cat). We have benefited from comments from Ben Bernanke, Christian Brownlees, John Cochrane, Marty Eichenbaum, Mark Gertler, Barbara Rossi, Paolo Surico, and Mark Watson and by participants at the NBER Summer Institute, Bicocca University, Universitat Pompeu Fabra, Bucharest International Network for Economic Research Workshop, Shanghai University of Finance and Economics, European Central Bank, Stockholm School of Economics, Sveriges Riksbank, Finnish Economic Association Congress, and NBER Macroeconomics Annual Conference. We acknowledge the financial support of the Spanish Ministry of Economy and Competitiveness through grants RyC-2016-20476 and ECO-2017-82596-P (Debortoli), ECO-2017-87827 (Galí), and ECO2015-67602-P (Gambetti), and through the Severo Ochoa Programme for Centres of Excellence in R\&D (SEV-2015-0563), and the Barcelona Graduate School of Economics. For acknowledgments, sources of research support, and disclosure of the authors' material financial relationships, if any, please see https://www.nber.org/chapters/c14241.ack.

1. Several central banks lowered their policy rates down to values below zero, thus proving that the latter should be seen a soft lower bound. From the point of view of our paper, what matters is the existence of a "perceived" value below which a given central bank is not willing to lower the policy rate, that is, an effective lower bound. In the case of the US economy, which is the focus of the present paper, zero appears to be the Fed's effective lower bound.

2. Many empirical papers have provided evidence on the unusual depth and persistence of downturns caused by financial crises. See, for example, Cerra and Saxena (2008), IMF (2009), and Reinhart and Rogoff (2009). Romer and Romer (2018) provide evidence suggesting that the degree of monetary and fiscal policy space greatly affects the macroeconomic performance in the aftermath of financial crises.

3. As Gust et al. (2017) themselves acknowledge, their estimates "are subject to considerable uncertainty as the 68 percent credible region does not exclude the possibility that the estimated effects of the ZLB constraint were much smaller or much larger" (2000).

4. Changes in volatility between the Great Moderation and the pre-Great Moderation periods have been uncovered by many authors (e.g., McConnell and Pérez-Quirós 2000; Stock and Watson 2002).

5. A similar methodology was used by Stock and Watson (2002) to test for a change in volatility during the Great Moderation.

6. See, for example, Galí (2015) for a derivation. By allowing for a nonzero steadystate inflation, we are implicitly assuming that prices are indexed to that variable. We also solved and simulated a fully nonlinear version of the model with price adjustment cost à la Rotemberg, obtaining very similar results to the linearized version considered here.

7. As in table 3, we allow for a period-specific mean during the binding ZLB episode.

8. These may include the change in the cyclical behavior of productivity emphasized in Galí and Gambetti (2009) as well as the change in monetary policy starting with Paul Volcker's tenure at the Fed uncovered in Clarida, Galí, and Gertler (2000).

9. We construct our data set using the following time series drawn from the Federal Reserve Economic Data database: real output per hour of all persons (nonfarm business sector; OPHNFB), hours of all persons (nonfarm business sector; HOANBS), civilian noninstitutional population (CNP16OV), GDP deflator (GDPDEF), and 10-Year Treasury Constant Maturity Rate (GS10).

10. It is worth noting that the reported bands take into account the uncertainty associated with the estimates of the reduced-form coefficients as well as the width of the setidentified impulse responses using sign restrictions.

11. See the appendix for a detailed description of the algorithm used.

12. Note that the monetary policy shock component for the $i$ th element of $\mathbf{x}_{t}$ is given by $C_{t}^{i 3}(L) \varepsilon_{t}^{m}$

13. We refer the reader to Galí and Gambetti (2009) for details. 


\section{References}

Andrade, Philippe, Jordi Galí, Hervé Le Bihan, and Julien Matheron. 2018. “The Optimal Inflation Target and the Natural Rate of Interest." Brookings Papers on Economic Activity, forthcoming.

Baumeister, C., and J. D. Hamilton. 2015. "Sign Restrictions, Structural Vector Autoregressions, and Useful Prior Information." Econometrica 83 (5): 196399.

Bernanke, Ben S., Jean Boivin, and Piotr Eliasz. 2005. "Measuring the Effects of Monetary Policy: A Factor-Augmented Vector Autoregressive (FAVAR) Approach." Quarterly Journal of Economics 120:387-422.

Bernanke, Ben S., Michael T. Kiley, and John M. Roberts. 2019. "Monetary Policy Strategies for a Low Rate Environment." Finance and Economics Discussion Series 2019-009, Board of Governors of the Federal Reserve System, Washington, DC. https://doi.org/10.17016/FEDS.2019.009.

Blanco, Andrés. 2019. "Optimal Inflation Target in an Economy with Menu Costs and Zero Lower Bound." American Economic Journal: Macroeconomics, forthcoming.

Campbell, Jeffrey R., Charles L. Evans, Jonas D. M. Fisher, and Alejandro Justiniano. 2012. "Macroeconomic Effects of Federal Reserve Forward Guidance." Brookings Papers on Economic Activity 43 (1): 1-54.

Cerra, Valerie, and Sweta C. Saxena. 2008. "Growth Dynamics: The Myth of Economic Recovery." American Economic Review 98 (1): 439-57.

Christiano, Lawrence, Martin Eichenbaum, and Sergio Rebelo. 2011. "When Is the Government Spending Multiplier Large?" Journal of Political Economy 119 (1): 78-121.

Christiano, Lawrence, Martin Eichenbaum, and Mathias Trabandt. 2015. "Understanding the Great Recession." American Economic Journal: Macroeconomics 7 (1): 110-67.

Clarida, Richard, Jordi Galí, and Mark Gertler. 2000. "Monetary Policy Rules and Macroeconomic Stability: Evidence and Some Theory." Quarterly Journal of Economics 105 (1): 147-80.

Cochrane, John H. 2018. "Michelson-Morley, Fisher, and Occam: The Radical Implications of Stable Quiet Inflation at the Zero Bound." NBER Macroeconomics Annual 2017 (32): 113-226.

Coibion, Olivier, Yuriy Gorodnichenko, and Johannes Wieland. 2012. “The Optimal Rate of Inflation in New Keynesian Models: Should Central Banks Raise Their Inflation Target in Light of the Zero Lower Bound?" Review of Economic Studies 20:1-36.

D'Amico, Stefania, and Thomas B. King. 2013. "Flow and Stock Effects of LargeScale Treasury Purchases: Evidence on the Importance of Local Supply." Journal of Financial Economics 108 (2): 425-48.

_ 2017. "What Does Anticipated Monetary Policy Do?" Working Paper 2015-10, Federal Reserve Bank of Chicago.

Datta, Deepa, Benjamin K. Johannsen, Hannah Kwon, and Robert J. Vigfusson. 2019. "Oil, Equities, and the Zero Lower Bound." Finance and Economics Discussion Series 2018-058, Board of Governors of the Federal Reserve System, Washington, DC.

Del Negro, Marco, Gauti Eggertsson, Andrea Ferrero, and Nobuhiro Kiyotaki. 2017. "The Great Escape? A Quantitative Evaluation of the Fed's Liquidity Facilities." American Economic Review 107 (3): 824-57. 
Del Negro, Marco, and Giorgio Primiceri. 2013. "Time-Varying Structural Vector Autoregressions and Monetary Policy: A Corrigendum." Staff Report No. 619, Federal Reserve Bank of New York.

Dordal-i-Carreras, Marc, Olivier Coibion, Yuriy Gorodnichenko, and JohannesWieland. 2016. "Infrequent but Long-Lived Zero-Bound Episodes and the Optimal Rate of Inflation." Annual Review of Economics 8 (1): 497-52.

Eggertsson, Gauti. 2011. "What Fiscal Policy Is Effective at Zero Interest Rates?" NBER Macroeconomics Annual 2010:59-112.

Fernández-Villaverde, Jesús, Grey Gordon, Pablo Guerrón-Quintana, and Juan F. Rubio-Ramírez. 2015. "Nonlinear Adventures at the Zero Lower Bound." Journal of Economic Dynamics and Control 57 (C): 182-204.

Galí, Jordi. 1999. "Technology, Employment and the Business Cycle: Do Technology Shocks Explain Aggregate Fluctuations?" American Economic Review 89:249-71.

. 2015. Monetary Policy, Inflation and the Business Cycle. An Introduction to the New Keynesian Framework and Its Applications. 2nd ed. Princeton, NJ: Princeton University Press.

Galí, Jordi, and Luca Gambetti. 2009. "On the Sources of the Great Moderation." American Economic Journal: Macroeconomics 1 (1): 26-57.

Gourio, François, and Phuong Ngo. 2018. "Risk Premia at the ZLB: A Macroeconomic Interpretation." Working Paper 2020-01, Federal Reserve Bank of Chicago.

Gust, Christopher, Edward Herbst, David López-Salido, and Matthew E. Smith. 2017. "The Empirical Implications of the Interest-Rate Lower Bound." American Economic Review 107 (7): 1971-2006.

Hamilton, James, and Jing Cynthia Wu. 2012. "The Effectiveness of Alternative Monetary Policy Tools in Zero Lower Bound Environments." Journal of Money, Credit and Banking 44 (s1): 3-46.

IMF (International Monetary Fund). 2009. World Economic Outlook, April 2009: Crisis and Recovery. Washington, DC: IMF.

Kiley, Michael T., and John M. Roberts. 2017. “Monetary Policy in a Low Interest Rate World." Brookings Papers on Economic Activity 2017 (1): 317-89.

Krishnamurthy, Arvind, and Annette Vissing-Jorgensen. 2011. "The Effects of Quantitative Easing on Interest Rates." Brookings Papers on Economic Activity 43:215-87.

McConnell, Margaret M., and Gabriel Pérez-Quirós. 2000. “Output Fluctuations in the U.S.: What Has Changed since the 1980s?" American Economic Review 90 (5): 1464-76.

Primiceri, Giorgio E. 2005. "Time Varying Structural Vector Autoregressions and Monetary Policy." Review of Economic Studies 72:821-52.

Reifschneider, David L., and John M. Roberts. 2006. "Expectations Formation and the Effectiveness of Strategies for Limiting the Consequences of the Zero Bound on Interest Rates." Journal of the Japanese and International Economies 20 (3): 314-37.

Reinhart, Carmen M., and Ken S. Rogoff. 2009. "The Aftermath of Financial Crises." American Economic Review: Papers and Proceedings 99 (2): 466-72.

Romer, Christina D., and David H. Romer. 2018. "Why Some Times Are Different: Macroeconomic Policy and the Aftermath of Financial Crises." Economica 85 (337): 1-40.

Rubio-Ramirez, J., D. Waggoner, and T. Zha. 2010. "Structural Vector Autoregressions: Theory of Identification and Algorithms for Inference." Review of Economic Studies 77:665-96. 
Smets, Frank, and Raf Wouters. 2007. "Shocks and Frictions in US Business Cycles: A Bayesian DSGE Approach." American Economic Review 97 (3): 586-606.

Stock, James, and Mark Watson. 2002. "Has the U.S. Business Cycle Changed and Why?" NBER Macroeconomics Annual 17:159-218.

Swanson, Eric T. 2018. "The Federal Reserve Is Not Very Constrained by the Lower Bound on Nominal Rates." Brookings Papers on Economic Activity 2018 (2): 555-72.

Swanson, Eric T., and John C. Williams. 2014. "Measuring the Effect of the Zero Lower Bound on Medium- and Longer-Term Interest Rates." American Economic Review 104 (10): 3154-85.

Uhlig, Harald. 2005. "What Are the Effects of Monetary Policy on Output? Results from an Agnostic Identification Procedure." Journal of Monetary Economics 52:381-419.

Wieland, Johannes. 2019. "Are Negative Supply Shocks Expansionary at the Zero Lower Bound?" Journal of Political Economy 127 (3): 973-1007.

Wu, Jing Cynthia, and Fan Dora Xia. 2016. "Measuring the Macroeconomic Impact of Monetary Policy at the Zero Lower Bound." Journal of Money Credit and Banking 48 (2-3): 253-91.

Wu, Jing Cynthia, and Ji Zhang. 2017. "A Shadow Rate New Keynesian Model." Working Paper no. 22856, NBER, Cambridge, MA. 